\title{
Preparation and characterization of different geometrical shapes of multi-bore hollow fiber membranes and application in vacuum membrane distillation
}

\author{
Elham M. El-Zanati*, Eman Farg, Esraa Taha, Ayman El-Gendi and Heba Abdallah
}

\begin{abstract}
Multi-bore hollow fiber membranes were prepared through phase inversion spinning process using new locally designed spinnerets of various geometrical shapes. The spun cylindrical-like, rectangular or ribbon-like, and triangular-like are prepared, dried, and characterized by scanning electronic microscope. Fibers of circular (seven, five, and four bores) shape, rectangular of five bores, and triangular of three bores were chosen to study the effect of both geometrical configuration and the number of bores on the amorphous structure and the mechanical properties of the membranes. Membrane geometry, surface amorphous, and bore arrangements are very sensitive to the operating conditions, especially the extrusion and drawing rates. Three polymeric blends of different compositions are used to prepare multibore hollow fiber membranes. This study revealed that the blend composition of PES 16\%, PVP 2\%, PEG 2\%, diethylene glycol 2\%, and NMP 78\% gives excellent mechanical properties. Optimization of the preparation conditions also developed, where the dope flow rate, the bore flow rate, and the air gap were $1.14 \mathrm{~cm}^{3} \mathrm{~s}^{-1}, 1.1 \mathrm{~cm} 3 \mathrm{~s}^{-1}$, and $0 \mathrm{~cm}$, respectively. Furthermore, this study proved that the circular arrangement has high mechanical strength. The prepared seven-MBHF membranes were applied in the membrane distillation process, a solution of $35 \mathrm{~g} / \mathrm{l} \mathrm{NaCl}$ was used to test the membrane performance, and the achieved flux and rejection were $28.32 \mathrm{~L} / \mathrm{m}^{2} \mathrm{~h}$ and $98.9 \%$, respectively. This performance demonstrated that the prepared membrane in this way is suitable to compete with conventional reverse osmosis technology that uses single track hollow fibers.
\end{abstract}

Keywords: Membrane, Hollow fiber, Multi-bore, Spinnerets, Design, Preparation, Characterization, Membrane distillation

\section{Introduction}

Nowadays, membranes are considered a keystone in chemical industries. The membrane structure is the essential property behind reliable applications, such as medical application, water purification, desalination, gas separation, membrane catalysis, and membrane reactors. Membrane separation processes can allow many advantages such as significant energy savings, low-cost modular construction, environmentally friendly, and clean technology.

\footnotetext{
*Correspondence: eelzanati@gmail.com

Chemical Engineering and Pilot Plant Department, Engineering Research Division, National Research Centre, 33 Bohouth St. Dokki, Giza 12622, Egypt
}

The membrane is a selective physical barrier that permits the separation of certain species by the incorporation of sieving and diffusion mechanisms (Bernardo et al. 2019; El-Zanati and Abdallah 2015). The membrane is potted into a casing unit to form a module. Mainly four modules configurations are commercially available; plate and frame, spiral wound, hollow fiber, and tubular module. The commonly used module's configuration is the spiral wound and hollow fiber. The spiral wound module has a small ratio of surface area per volume; it tolerates high pressures processes, and dominates the market of high-pressure separation processes as nano-filtration (NF) and reverse osmosis (RO).
Springer Open 
While the hollow fibers modules are prevailing in relatively low-pressure filtration processes as ultra-filtration (UF), hemodialysis, and membrane bioreactors (MBR). Since a single piece of hollow fiber has relatively weak mechanical strength, it may be broken easily during its use to become a source of operational difficulties. Besides, polymeric hollow fibers may elongate, twist, and entangle with one another, creating problems for backwashing and fouling removal (El-Zanati and Abdallah 2015).

The multi-bore hollow fiber (MBHF) membranes are new emerging configurations, which could combine the characteristics of flat sheet and hollow fiber membranes and withstand high pressures and have a large surface area (Wang et al. 2014; Haase et al. 2017). The MBHF structure provides an improved mechanical strength required for different applications and development the membrane performance. Moreover, the MBHF membrane has high stability and durability compared with the conventional single-bore hollow fiber (Abdallah et al. 2015; El-Zanati and Abdallah 2015; Haase et al. 2017). The single-bore hollow fibers break and entangle during continuous operations, but the new generation of hollow fiber membranes of multi-bore configuration shows remarkable improvement.

The MBHF membranes are prepared using the traditional spinning process. The polymer solution extruded through the spinnerets; then, the polymers solution is coagulated through an exchange of solvent with a miscible non-solvent coagulation bath. The bores are formed by passing the bore fluid through the needles of the spinning nozzle. The spinning process depends on several parameters, such as air gap length, dope solution viscosity, dope extrusion flow rate, coagulation bath temperature, composition, and take-up speed. The polymeric dope solution is a blend of polymers, solvent, and often one or more additives. The increasing polymer concentration in the dope solution results in more polymer mass fraction, higher solution viscosity, and consequently decreases the membrane porosity and increases of membrane thickness. Membrane preparation uses different polymers of different properties. Membrane preparation with high selectivity and high permeability is necessary for all applications. Different additives are necessary to improve the performance of membranes (Liu et al. 2011). Numerous researchers developed novel engendering membranes of great performance and excellent mechanical properties with MBHF configuration and compared the performance of these membranes with the conventional single-bore hollow fibers especially in membrane distillation (Teoh et al. 2011; Chung and Wang 2012; Lu et al. 2016; El-Zanati et al. 2020).

This article is aiming at the study of the preparation of the second hollow fiber membrane

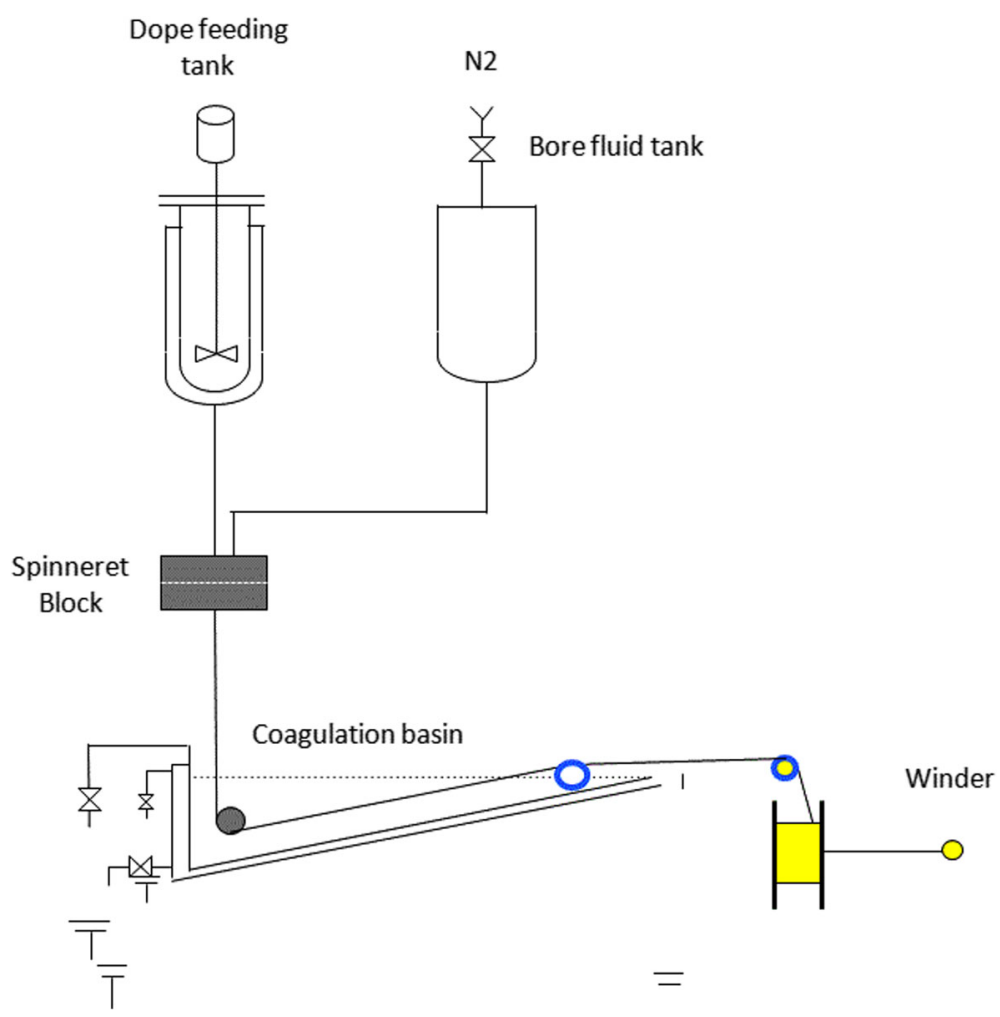

Fig. 1 Process design of MBHF membrane spinning 


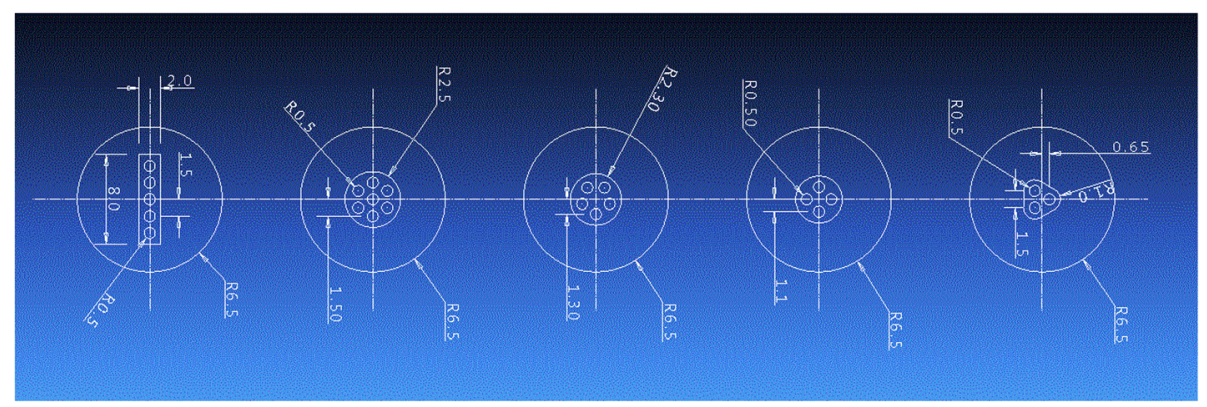

Fig. 2 Detailed nozzle design. All dimensions in millimeters

generation: multi-bore hollow fiber membrane, which has maximum surface area per unit volume and has both flat sheet and hollow fiber membrane properties.

\section{Methods}

\section{Spinning system}

\section{Process design}

This part aims to demonstrate the process design of the membrane spinning, the dope solution prepared in a mechanically stirred vessel, and the bore fluid (water) stored in a surge tank. Both dope and bore fluids are entering the spinning block, to pass inside the spinneret, the raw fiber goes to the coagulation bath to form for the crystalline fibers. Figure 1 illustrates the integrated system of preparation of MultiBore Hollow Fiber Membranes. It consists of the following:

1. A tank provided with a mechanical stirrer to mix the polymer, additives with solvent, and a bore fluid feeding tank

2. The spinning block includes the spinneret placed in a particular room

3. The coagulation bath at which the MBHF passes through guide rollers

4. The collecting winder of the MBHF membrane

\section{Basic design of spinnerets and spinning block Spinneret design}

Many spinnerets of different geometrical configurations designed to prepare and evaluate the performance of several multi-bore hollow fiber membranes. The tested membranes specifically are circular, rectangular, and triangular shapes (Fig. 2). The spinnerets hold in a stainless-steel block.

A triangular shape coagulation bath is designed to obtain the fibers, which are gathered after coagulation on a collecting stainless-steel winder.

\section{System implementation}

Spinnerets and spinning block

All designed spinnerets and spinning blocks are manufactured in the local market of stainless-steel using the laser technology. Figure 3 illustrates the fabricated spinnerets of circular, rectangular, and triangular configuration.

\section{Integrated system}

The spinning system consists of two peristaltic pumps to the simultaneous feed of the dope solution and the bore fluid at specified flow rates to create the multi-bore hollow fiber membranes. The spinning system with all different spinnerets implemented and assembled as a preparation line illustrated in Fig. 4.

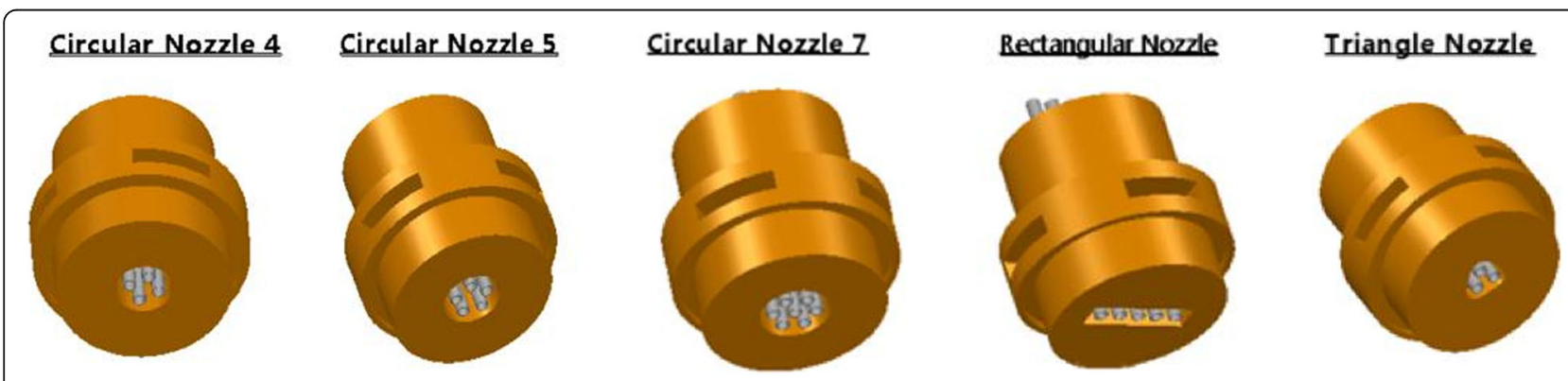

Fig. 3 Detailed mechanical drawing of all nozzles (all dimensions in millimeters) 


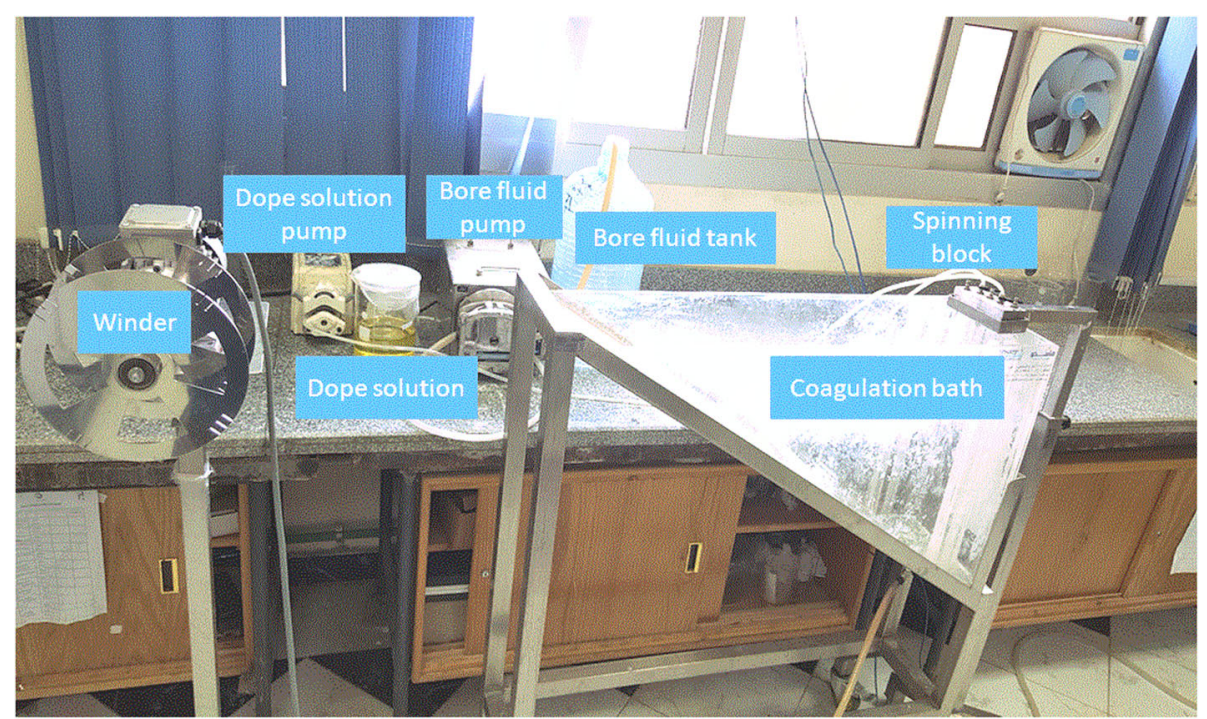

Fig. 4 The integrated spinning system

\section{Membrane preparation \\ Materials}

Polyethersulfone (PES Ultrason E6020P) of MW 58, 000 supplied by BASF Germany was used to prepare the dope solution. This polymer absorbs moisture; therefore, it was dried for more than $12 \mathrm{~h}$ at 100 $105^{\circ} \mathrm{C}$ before use. The solvent N-Methyl-pyrrolidone (NMP), clear colorless to plate yellow, liquid, is supplied by Alfa Aesar Germany (A12260). Polyvinyl pyrrolidone, $25,000 \mathrm{~g} /$ mole molecular weight, is supplied by Alfa Aesar Company. Polyethylene glycol (EG) (reagent grade, MW; 400) were used as additives to improve the membrane mechanical properties, clear colorless liquid, is supplied by Loba Chemie Pvt. Ltd. Diethylene glycol (for synthesis with MW; 106.12) was purchased from Merk Schuchardt OHG, Germany.

\section{Preparation}

The multi-bore hollow fiber membranes are prepared with PES, by phase inversion via immersed precipitation method. The dope solution was prepared by dissolving PES polymer in NMP and adding PVP as pore former, also supplementing diethylene glycol and acetonitrile to improve the membrane properties; the temperature was about $20 \pm 2{ }^{\circ} \mathrm{C}$ and stirred mechanically at $400 \mathrm{rpm}$ for $4 \mathrm{~h}$. The obtained homogeneous polymer solution was kept for $24 \mathrm{~h}$ to remove the air bubbles. Figure 5 demonstrates the preparation steps.

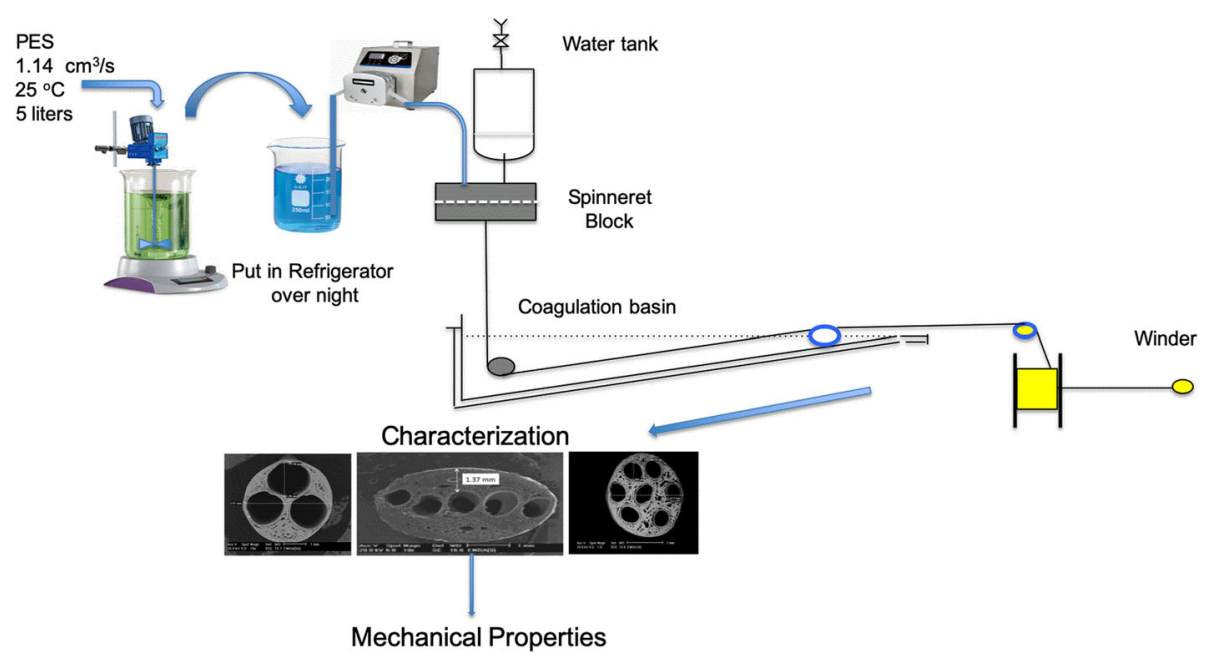

Fig. 5 Multi-bore hollow fiber (MBHF) membrane preparation 
Table 1 Polymer blends composition

\begin{tabular}{lllllll}
\hline Polymer blend & PES\% & PEG\% & PVP\% & Diethylene glycol\% & Acetonitrile\% & NMP\% \\
\hline PB1 & 16 & 4 & - & - & 2 & 78 \\
PB2 & 16 & - & 4 & - & 2 & 78 \\
PB3 & 16 & 2 & 2 & 2 & - & 78 \\
\hline
\end{tabular}

\section{Characterization}

Morphology study by SEM Membrane morphology was investigated by a field-emission scanning electron microscope (SEM). Which used to characterize the membrane morphology and surface topography, the dry samples were covered with a gold sputtering to provide electrical conductivity.

Mechanical properties The mechanical properties of prepared membranes were studied. The tensile strength and elongation percentage were measured using an Instron tensiometer (INSTRON-5500R, Instron Corp.). The elongation rate was $10 \mathrm{~mm} / \mathrm{min}$, and the starting gage length was $50 \mathrm{~mm}$. The gage length of the dumbbell tensile specimens was $6.2 \mathrm{~mm}$. The specimens of membranes were placed between the grips of the testing machine. The tensile strength and elongation\% were calculated with the accuracy of the measurement is within $\pm 5 \%$.

\section{Study of the influencing parameters}

The parametric study of preparation conditions of MBHF membranes had investigated. The influencing parameters of membrane preparation are the flow rate of the dope blend, the flow rate of bore fluid, the distance between the block and water surface at the coagulation bath (the air gap distance), and take-up collecting speed. In this study, three polymeric blends (PB1, PB2, and PB3) were investigated; Table 1 illustrates their compositions.

Table 2 summarizes the spinning conditions of the three dope blends.
Table 3 summaries the ranges of the studied influencing parameters.

\section{Application of MBHF in membrane distillation Membrane preparation}

A hydrophobic porous membrane was developed and applied in membrane distillation for water desalination. The membrane was prepared by the early mentioned spinning process (polyvinylidene fluoride (PVDF 13\%), ethylene glycol (EG 5\%), lithium chloride ( $\mathrm{LiCl} 5 \%)$, and N-methyl-2-pyrrolidone (NMP 77\%)). Therefore, the polymer (PVDF) was dissolved in (NMP) with the addition of (EG) and $(\mathrm{LiCl})$ as pore former at around 50 ${ }^{\circ} \mathrm{C}$, while stirring mechanically at $400 \mathrm{rpm}$ for $4 \mathrm{~h}$; then, it was degassed overnight.

Scanning electronic microscopy (SEM) was used to characterize the prepared membrane morphology and surface topography. The contact angle of the prepared PVDF membranes was also determined (SCA 20, OCA 15EC) using the sessile drop method at preparation and finishing of cellulosic fibers, Textile Research Division, NRC.

The membrane porosity is calculated by the Eq. (1):

$$
\text { Porosity } \%=\left(\frac{V_{\mathrm{p}}}{V_{\mathrm{m}}}\right) \times 100
$$

where $V_{\mathrm{p}}$ is the pores volume and $V_{\mathrm{m}}$ is the volume of the membrane sample.

\section{Vacuum membrane distillation (VMD) experiment}

The performance of the fabricated PVDF-MBHF membranes was evaluated with a vacuum membrane distillation (VMD) unit, as shown in Fig. 6. The feed water was a synthetic $\mathrm{NaCl}$ solution $(35000 \mathrm{ppm})$, at $65^{\circ} \mathrm{C}$ and the

Table 2 Spinning initial conditions

\begin{tabular}{llll}
\hline Spinning conditions & PB1 & PB2 & PB3 \\
& PES/PEG/AN/NMP & PES/PVP/AN/NMP & PES/PEG/PVP/DG/NMP \\
\hline Bore fluid & Water & \\
Dope fluid flow rate, $\mathrm{cm}^{3} / \mathrm{s}$ & 1.14 & \\
Bore fluid flow rate, $\mathrm{cm}^{3} / \mathrm{s}$ & 0.46 \\
Air gap distance, $\mathrm{cm}$ & 2 \\
Take-up rate & Free fall \\
$T_{1}{ }^{\circ} \mathrm{C}$ & $25 \pm 2$ & \\
\hline
\end{tabular}


Table 3 Spinning conditions ranges

\begin{tabular}{ll}
\hline Dope composition & $\begin{array}{l}\text { PES 16\%, PVP2\%, PEG 2\%, diethylene } \\
\text { glycol 2\%, NMP78\% }\end{array}$ \\
\hline Bore fluid & Water \\
Dope flow rate, $\mathrm{cm}^{3} / \mathrm{s}$ & $0.77,0.92,1.14,1.47,1.92,2.17$ \\
Bore fluid flow rate, $\mathrm{cm}^{3} / \mathrm{s}$ & $0.27,0.55,0.7,1,1.2,2.4$ \\
Air gap distance, $\mathrm{cm}$ & $0,1,2,3,4,5,6$ \\
Coagulation bath & Water \\
Temperature, ${ }^{\circ} \mathrm{C}$ & 25 \\
Take-up speed & Free fall \\
\hline
\end{tabular}

feed flow rate of $8.6 \mathrm{~cm}^{3} / \mathrm{s}$ and the vacuum at the permeate side adjusted at 1000 Pascal (absolute pressure). The permeate collected and condensed, and the volume and salinity reported. The water permeation flux $\left(J_{\mathrm{W}}\right)$ calculated according to the Eqs. (2) and (3).

$$
J_{\mathrm{W}}=\frac{V}{A}
$$

where $J_{\mathrm{W}}$ is the membrane flux, $\mathrm{Lm}^{-2} \mathrm{~h}^{-1} ; V$ is the volumetric flow rate of the permeate, $\mathrm{L} / \mathrm{h}$; and $A$ is the effective membrane area, $\mathrm{m}^{2}$. The salt rejection (SR) obtained using the Eq. (2), where $C_{\mathrm{P}}$ is the final salt concentration of the permeate stream and $C_{\mathrm{F}}$ is the initial salt concentration of the feed.

$$
\mathrm{SR}=\left(1-\frac{C_{\mathrm{P}}}{C_{\mathrm{F}}}\right) \times 100
$$

\section{Results and discussions \\ Effect of influencing parameters \\ Geometrical configuration}

The manufactured circular spinnerets of 4, 5, and 7 bores, the rectangular of 5 bores, and the triangular of 3 bores did use to develop the membranes using the blend PB1 (PES 16\%, PEG 4\%, AN 2\%, and NMP 78\%) at the initial conditions described in Table 1. Figure 7 depicts the scanning electron microscopy (SEM) graphs of the fabricated membranes. The circular spinnerets of 4 and 7 bores give uniform membranes of distinguished straight channels without any imperfections, while the other circular spinneret (5 bores) was of non-uniform thickness, although it maintains straight channels.

\section{Effect of dope solution composition}

The circular spinneret of seven bores used to study the effect of polymer composition on the preparation steps and the rheological behavior of the dope solution and the perfectness of the produced membrane as well. Figure 8 demonstrates the steady extrusion of the polymer solution from the die exit, which confirms the stability effect of the solution viscosity and its rheological

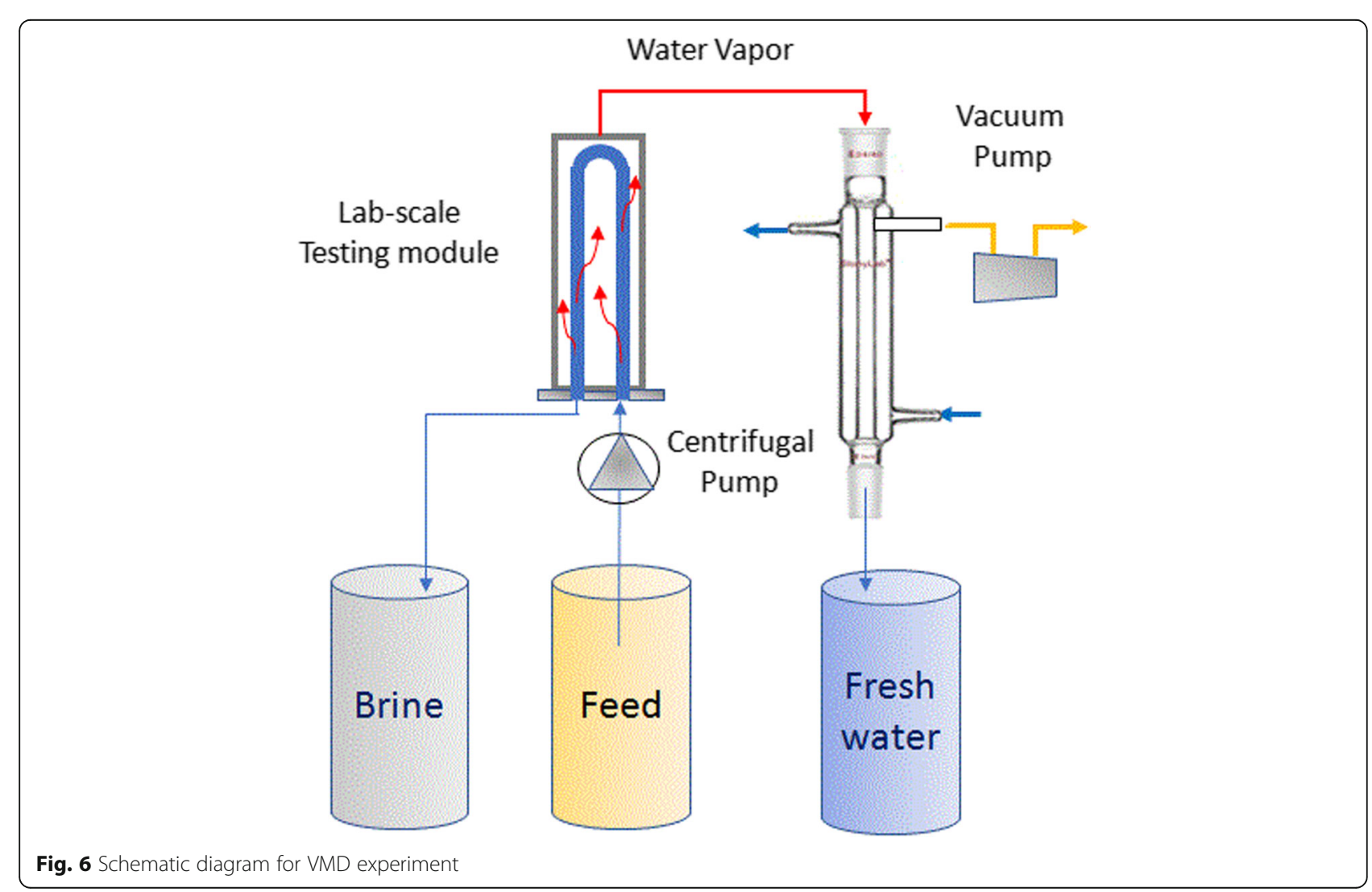



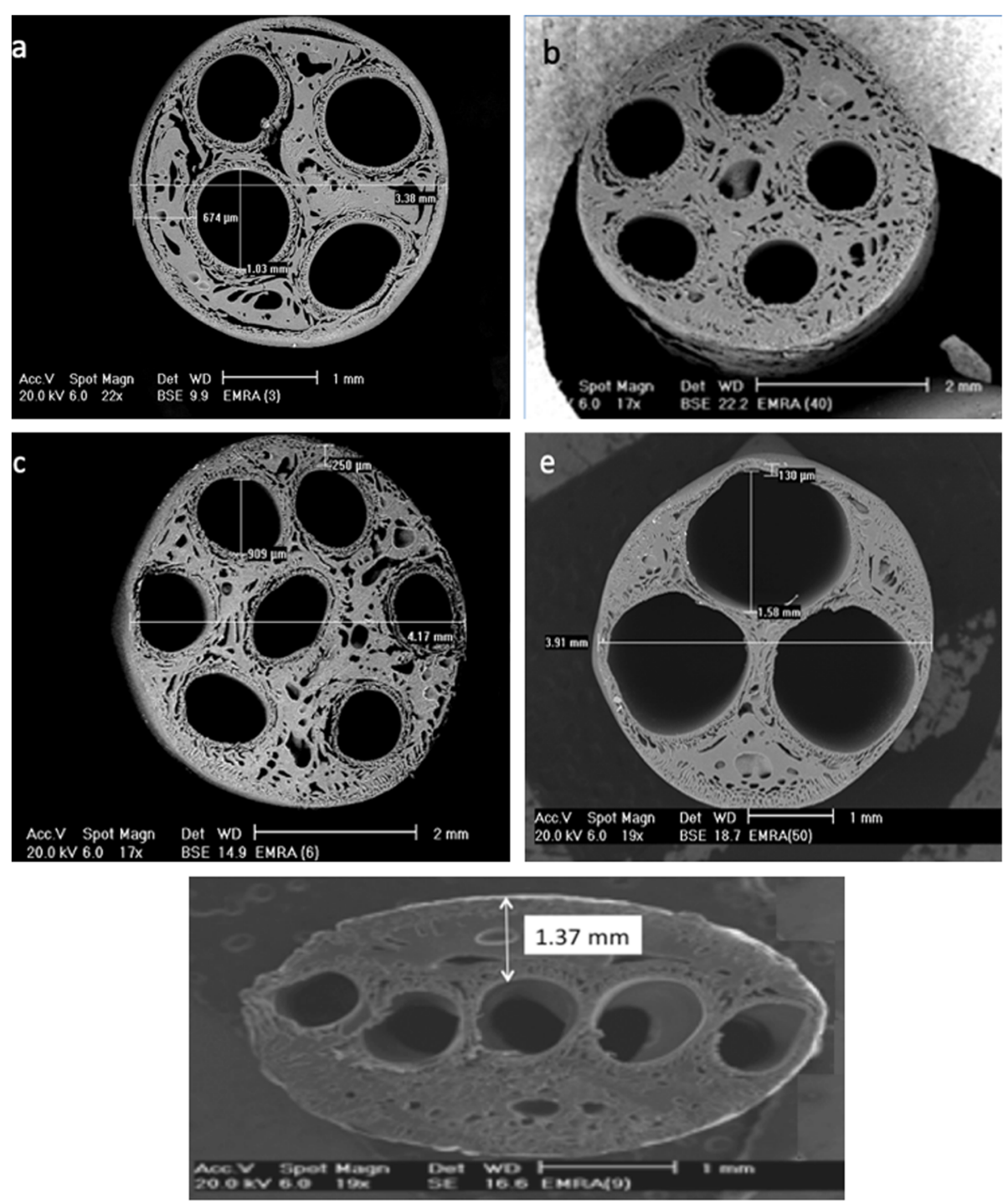

Fig. 7 SEM graphs of different geometrical shapes of MBHF membranes

behavior. The rate of withdrawal of the fibers allows excellent uniformity of bore diameters and gives uniform membrane thickness (Liu et al. 2011; Agboola et al. 2011).

The membranes were prepared with the three different dope blend compositions, as mentioned in Table 1: PB1 (PES 16\%, PEG 4\%, acetonitrile $2 \%$ and NMP $78 \%$ ), PB2 (PES 16\%, PVP 4\%, acetonitrile $2 \%$ and NMP $78 \%$ ), and PB3 (PES 16\%, PEG 2\%, PVP 2\%, diethylene glycol 2\%, and NMP 78\%). The membranes were prepared according to the operating conditions displayed in Table 2, the bore fluid was the water at a flow rate of $0.46 \mathrm{~cm}^{3} / \mathrm{s}$, and the dope fluid flow rate was $1.14 \mathrm{~cm}^{3} / \mathrm{s}$, at the air gap distance of $2 \mathrm{~cm}$ and using the free-fall technique to collect the fibers manually. The preparation instabilities usually occurred in the downstream process, i.e., in the coagulation step; these instabilities lead to sequential and propagated changes in the bore diameter and outer shape imperfection as displayed in Fig. 9, as well as roughness, wrinkles, peeling, exfoliating, and in membrane pore. It is observed that the formation of surface inadequacies and faults of (PB1) propagated and caused deformation in bore diameters and non-uniformity in membrane thickness (Fig. 9a, PB1); also, the surface of the final product has peels, exfoliates, and wrinkles on the external surface (Fig. 11b, PB1; Fig. 9b, PB1). It also perceives irregularities in bore diameters, which may refer to as the low viscosity of the dope fluid (Fig. 10), and relatively low viscosity of bore fluid (water). Furthermore, the bore fluid is channeled inside the part of the least flow resistance of the nozzles and may cause wrinkles and peeling. Glycerol is a viscous bore fluid that will 


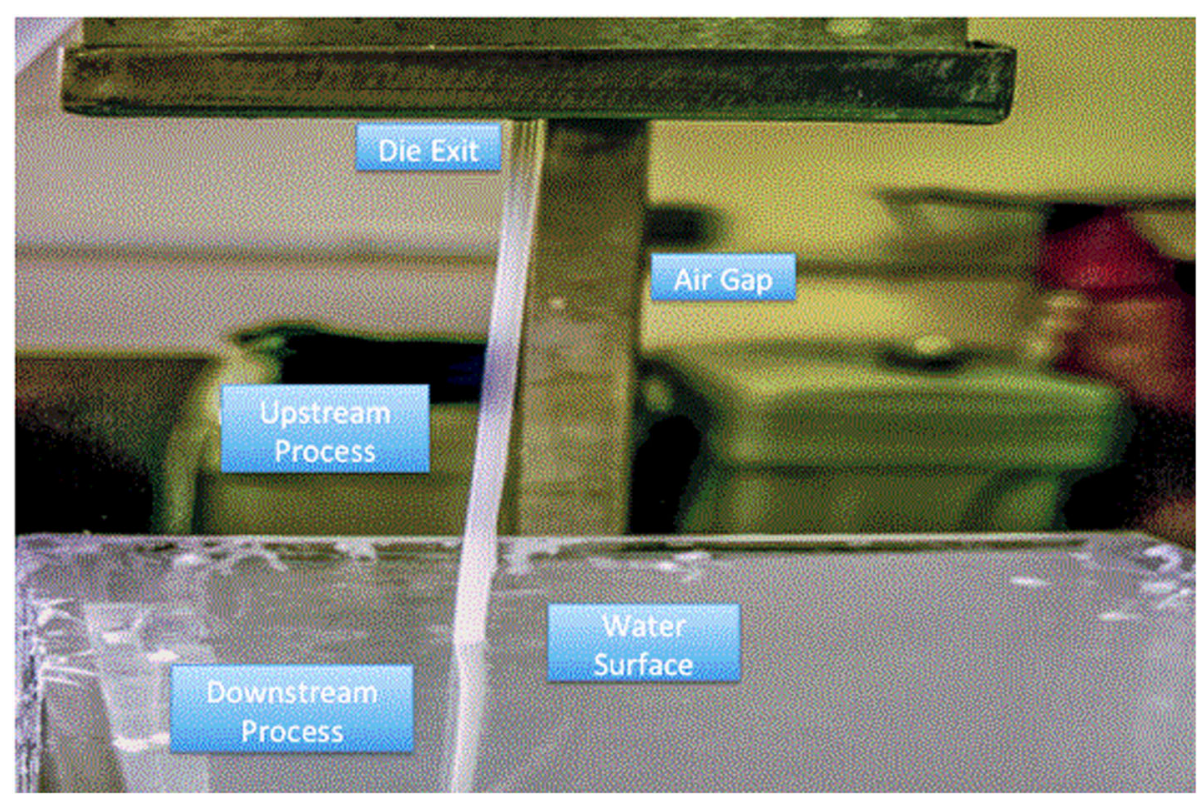

Fig. 8 Stable extrusion from die exit into water coagulation bath

use to overcome this problem. The development of the instabilities of the membranes refers to the low viscosity of the polymer solution (PB1), which was $800 \mathrm{cP}$ at temperature $27^{\circ} \mathrm{C}$. A new blend (PB2) that includes PVP is prepared with an additive to enhance the pore formation and blend viscosity $\left(1700 \mathrm{cP}\right.$ at temperature $\left.27^{\circ} \mathrm{C}\right)$; this formula suppresses, also, the undesirable instabilities of the dope polymer solution (Liu et al. 2011; Agboola et al. 2011; Bonyadi and Mackley 2012; Peng et al. 2011; Hua et al. 2014; Ullsperger and Válek 2018; Wang et al. 2014), although the viscosity increased; the formation of wrinkles still occurs on the external surface of the membrane, as illustrated in (Fig. 9b, PB2). The addition of diethylene glycol (plasticizing agent) to the dope blend enhances the fiber characteristics (PB3) and improves the elasticity of the membrane fibers due to increases in the viscosity $\left(2550 \mathrm{cP}\right.$ at temperature $\left.27^{\circ} \mathrm{C}\right)$. The membrane wall surface became smooth and free of wrinkles as well as the appearance of bores, which is getting more rounded (Fig. 9b, PB3).

Henceforth, the best polymeric blend (MBHF) used in this study at the mentioned conditions of membrane preparation is the blend of PB3 composition.

The rheological properties of the three blends: PB1, PB2, and PB3 were studied. The results revealed that the viscosity of polymer blend decreased with increasing the temperature of the polymer solution, whereas the physical behavior of the blend viscosity is linearly decreased from 3150 to $800 \mathrm{cP}$ at 23 to $50^{\circ} \mathrm{C}$ respectively (PB3); the three blends behave as Newtonian fluid under such conditions. Furthermore, PB3 has a relatively higher viscosity than the other blends (PB1, PB2) at any temperature. The rheological properties are dependent on the flowing and fluidity of the molten polymer during the spinning process. Meanwhile, it affects the membrane characteristics and its amorphous structure, such as pore size, pore distributions, porosity, tensile strength, and other mechanical properties (Liu et al. 2011; Agboola et al. 2011; Bonyadi and Mackley 2012; Peng et al. 2011; Hua et al. 2014; Ullsperger and Válek 2018; Wang et al. 2014).

\section{Effect of dope solution flow rate}

Figure 11 shows the SEM photos of circular membranes spun obtained from different flow rates of dope solution $\left(0.77,0.92,1.14,1.47,1.92,2.17 \mathrm{~cm}^{3} / \mathrm{s}\right)$ at fixed bore fluid flow rate, $1.1 \mathrm{~cm}^{3} / \mathrm{s}$ and at 0 air gap distance, as reported in Table 3. Also, it illustrates clearly, the trend of approximate symmetric morphology transition of the holes and the size of the formed bore (Fig. 11a-c). Increasing the dope solution flow rate at the fixed bore fluid flow rate of $1.1 \mathrm{~cm}^{3} / \mathrm{s}$ leads to deforming the shape of the hole, as a result of delay demixing. The coalescence between adjacent holes is observed in Fig. 11d; most of the inner skin is still in the fluid state, while the outer surface of the membrane starts to solidify. As a result, the more fluid-like dope tends to flow or rearrange itself to formless lumen hole to minimize the surface energy, where the irregular contour generated because of the uneven and unbalanced stresses (Wang and Chung 2012; Li et al. 2019). Figure 11c indicates the excellent appearance of circular 7 MBHF membranes using dope and bore fluid flow rates of 1.14 and $1.1 \mathrm{~cm}^{3} / \mathrm{s}$, respectively. Figure $11 \mathrm{~b}$ indicates a decrease in bore diameters 

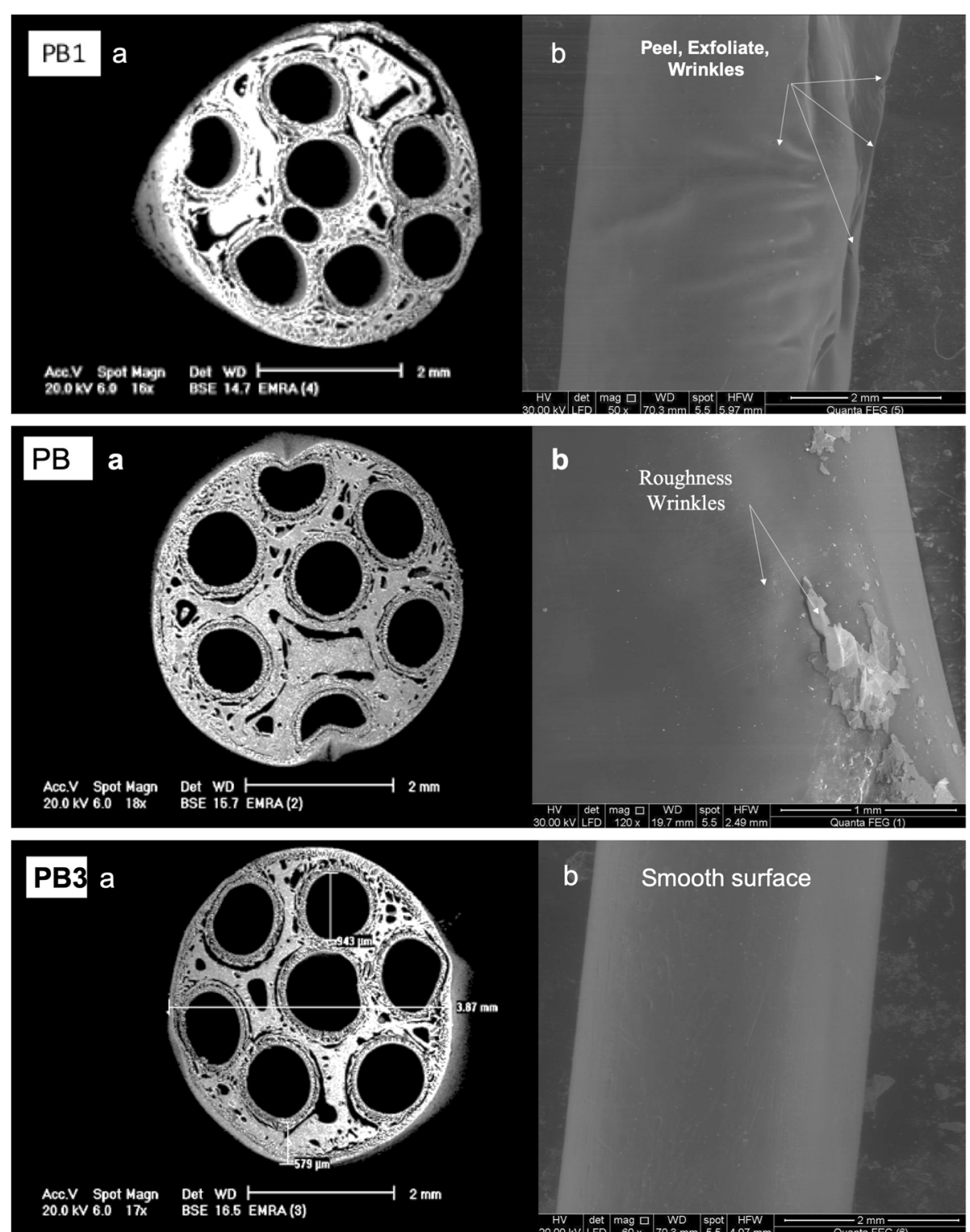

Fig. 9 SEM images of circular (seven-bore hollow fiber) membrane at different dope blend compositions

using flow rates of the dope polymer solution and bore fluid 0.92 and $1.1 \mathrm{~cm}^{3} / \mathrm{s}$, respectively. The small flow rate of both dope solution leads to form a dense layer due to the delay coagulation of the nascent MBHF membrane. Also, some bores are closed or collapsed, due to the high dope solution and low bore fluid flow rates, Fig. 11d and e. Accordingly, the optimum configuration is in Fig. 11c at dope and bore fluid of 1.14 and $1.1 \mathrm{~cm}^{3} / \mathrm{s}$, respectively, and 0 air gap distance (M. M. Teoh et al. 2011).

\section{Effect of bore fluid flow rate}

Figure 12 demonstrates the SEM photos of circular 7 BHF membranes spun for dopes flow rate $1.14 \mathrm{~cm}^{3} / \mathrm{s}$ with various bore fluid flow rates $(0.27,0.7,1.1,1.8$, $\left.2.2 \mathrm{~cm}^{3} / \mathrm{s}\right)$. As perceived in Fig. 12a-c, membrane samples have excellent appearance, good uniformity in bore diameters and membrane thicknesses, and the deformation in the cylindrical 7 BHF appeared due to increasing the bore fluid flow rate more than $1.1 \mathrm{~cm}^{3} /$ s. The best flow rate of bore fluid was $1.1 \mathrm{~cm}^{3} / \mathrm{s}$ (inner fluid), which is approximately equal to the dope flow rate, $1.14 \mathrm{~cm}^{3} / \mathrm{s}$ (outer fluid); this situation provides equilateral stresses in all directions of the membrane; hence, a uniform membrane thickness will be achieved. Figures $12 \mathrm{a}$ and $\mathrm{b}$ indicate that the decreased bore diameter and the increased membrane thickness due to a high dope flow rate of $1.14 \mathrm{~cm}^{3} / \mathrm{s}$ comparing with low bore fluid 0.27 and $0.7 \mathrm{~cm}^{3} / \mathrm{s}$. 


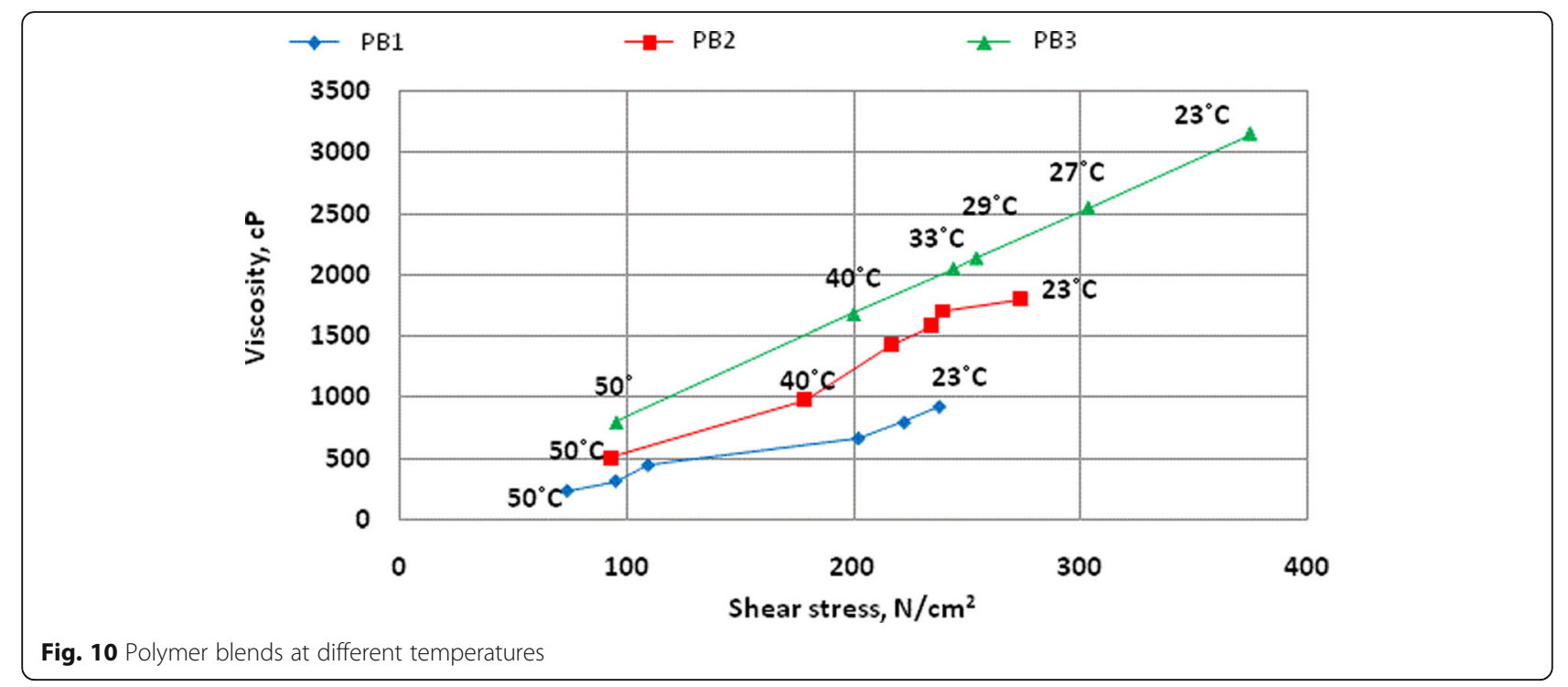

Figure 12c designates the appearance of equal bore diameters and approximate regularity in the bores arrangement using dope flow rate $1.14 \mathrm{~cm}^{3} / \mathrm{s}$ and bore fluid $1.1 \mathrm{~cm}^{3} / \mathrm{s}$. Figures $12 \mathrm{~d}$ and e $\left(1.8,2.2 \mathrm{~cm}^{3} / \mathrm{s}\right)$ indicate nonhomogeneous bores distribution and membrane thickness. Accordingly, the optimum conditions are at a dope flow rate of $1.14 \mathrm{~cm}^{3} / \mathrm{s}$ and bore fluid $1.1 \mathrm{~cm}^{3} / \mathrm{s}$ (Wang et al. 2014; Wang and Chung 2012; Li et al. 2019)..

\section{Effect of air gap}

The influence of air gap distance on the circular 7 BHF membrane morphology was studied at different air gap distances $(0,1,3$, and $6 \mathrm{~cm})$ at the dope solution and bore fluid flow rates of 1.14 and $1.1 \mathrm{~cm}^{3} / \mathrm{s}$, respectively.
Figure 13 illustrates the EMS photographs of 7 BHF membranes. The increase of air gap length produces a membrane of small outside diameter, attributed to the elongation, which is developed by the gravitational force. However, the air gap provides uneven stress, while the slow phase inversion takes place at the membrane outside the surface. Therefore, an increasing air gap over $3 \mathrm{~cm}$ forms deformation in the 7 BHF membranes in the radial direction due to the stress that exists under gravitational and elongation forces (Li et al. 2019; Teoh et al. 2011).

\section{The mechanical properties of all MBHF membranes}

The mechanical properties of all MBHF membranes are investigated, at the different conditions: the dope

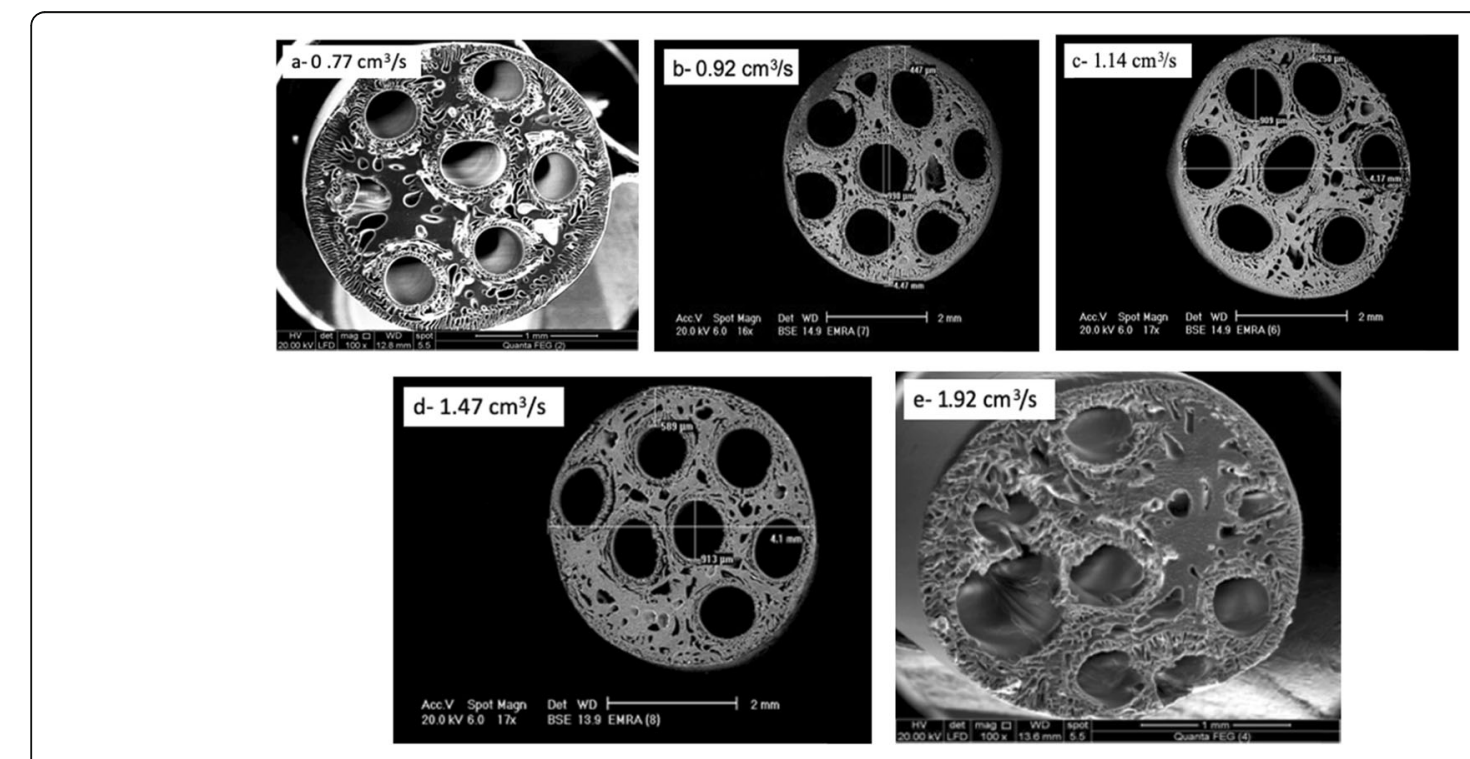

Fig. 11 Effect of dope solution on the 7 MBHF membrane morphology 

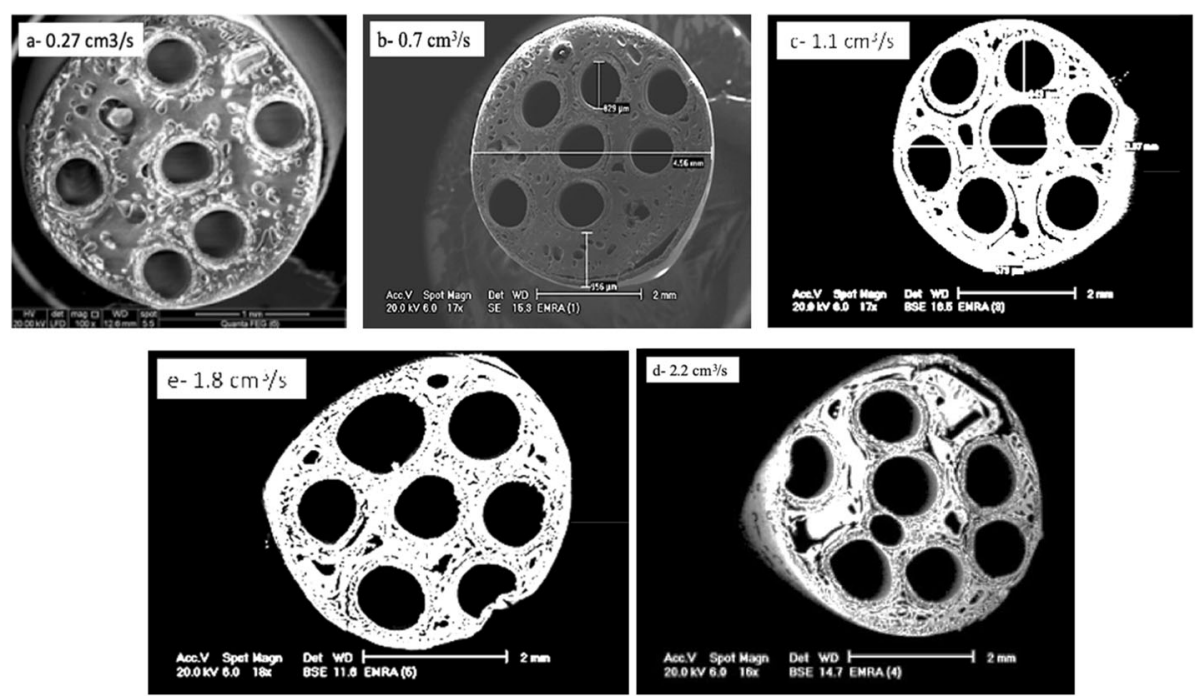

Fig. 12 Effect of bore fluid on the 7 BHF morphology

solution flow rate ranges from 0.4 to $2.4 \mathrm{~cm}^{3} / \mathrm{s}$, the bore fluid flow rate 0.27 to $2.4 \mathrm{~cm}^{3} / \mathrm{s}$, and air gap distance 0 to $6 \mathrm{~cm}$. Figure 14 illustrates the tensile strength and elongation \% of circular multi-bore hollow fiber (CMBHF), rectangular multi-bore hollow fiber (RMBF), and triangular multi-bore hollow fiber (TMBHF) membranes. For all types of bore arrangements, the circular bore fiber membranes possess the highest tensile strength and elongation; $82.3 \mathrm{~kg} / \mathrm{cm}^{2}$ and $22 \%$, respectively, at dope solution flow rate 1.14 $\mathrm{cm}^{3} / \mathrm{s}$; the rectangular and triangular configurations are coming next. While the elongation of the TMBHF membrane is nearly equal that of CMBHF and higher than the RMBHF membranes, which attributed to the high elasticity of TMBHF than the ribbon-like RMBHF, therefore, the bore geometrical pattern
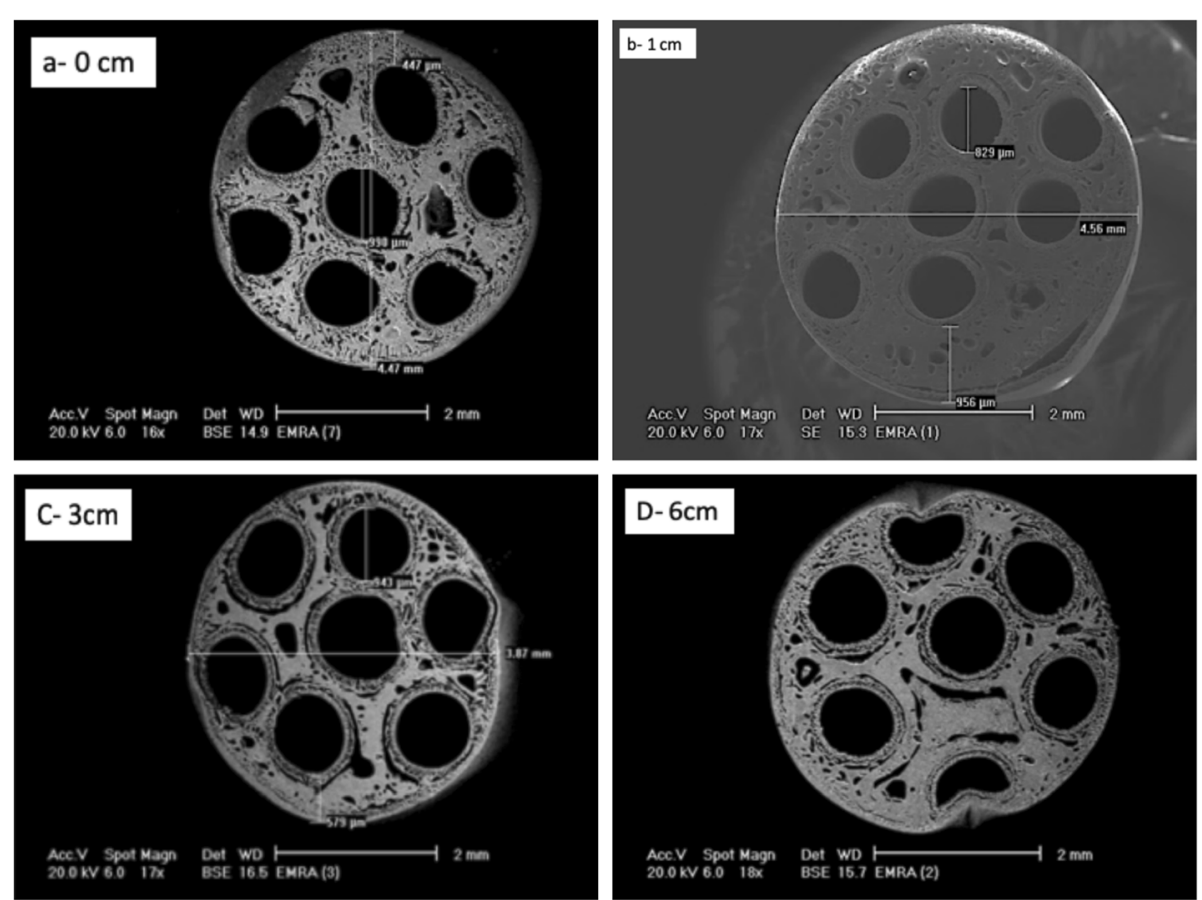

Fig. 13 Effect of air gap distance on (7 BHF) membrane 

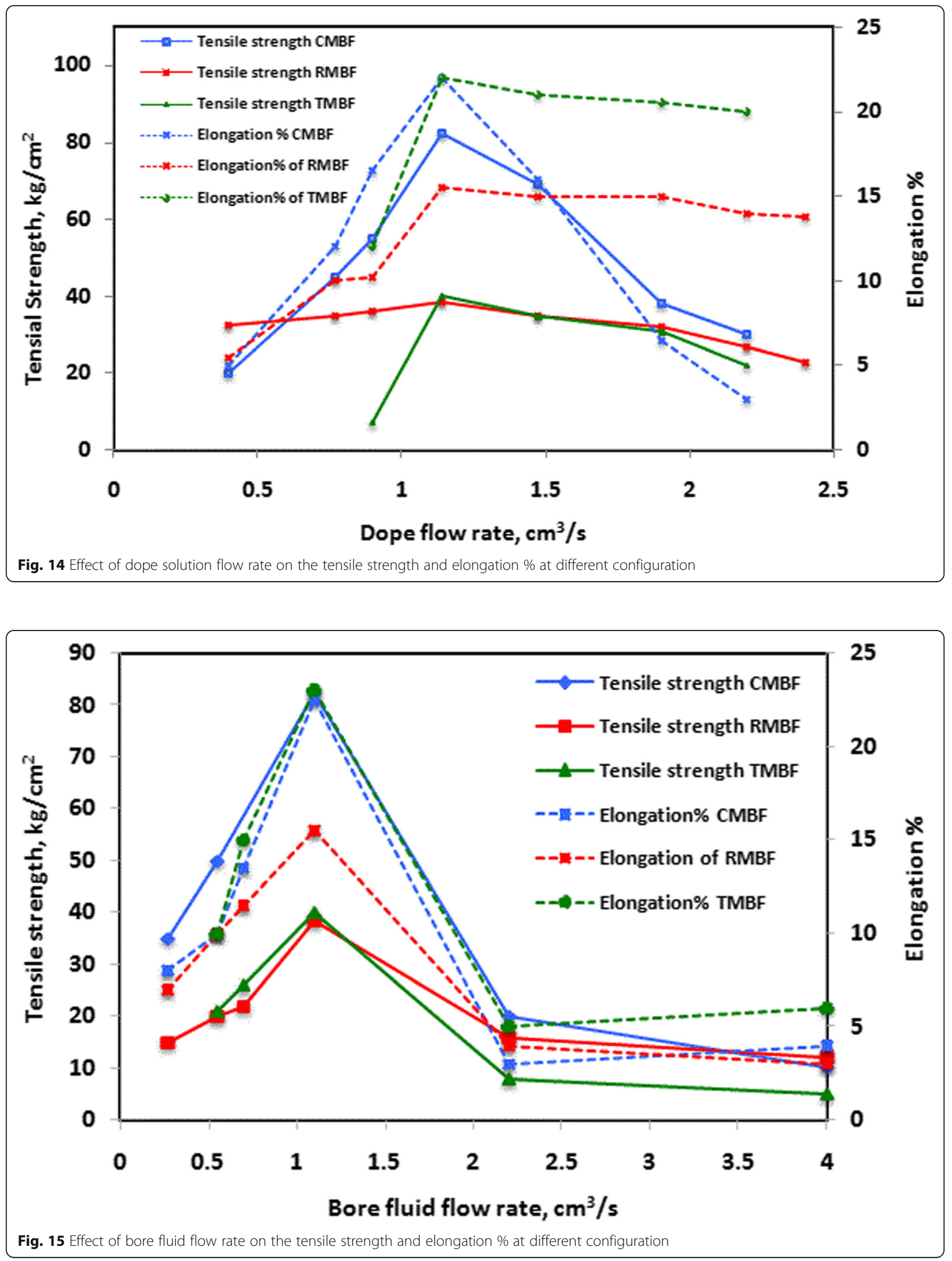

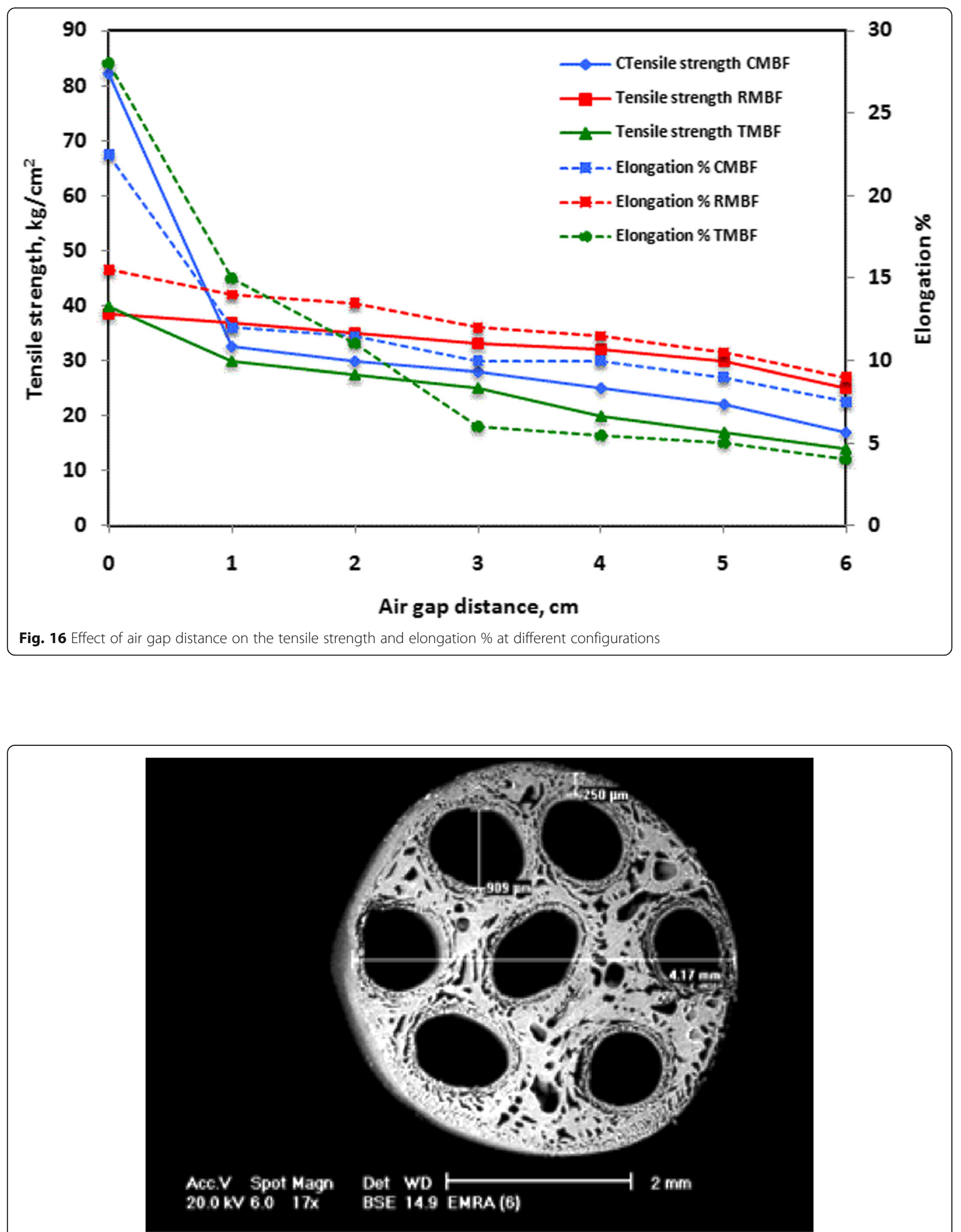

Fig. 17 SEM of the PVDF hydrophobic porous membrane 


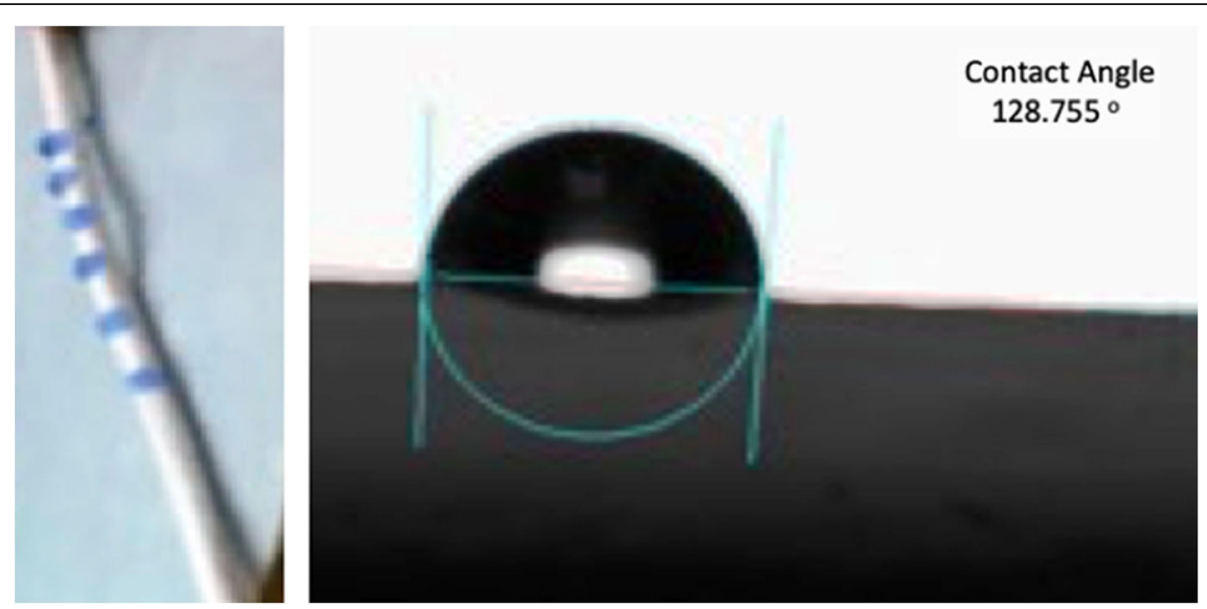

Fig. 18 Water contact angles of the PDVF membranes

enables to raise the membrane elasticity. CMBHF membranes could endure high load before it cracks, it can sustain in the backwash, or fouling removal, while applications particularly in water desalination and water treatment. The maximum tensile strength of the circular type is attributed to the self-support of the perfect cylindrical channel arrangement. The TMBHF behaves as CMBHF type, but to a lesser extent, this behavior attributed to the decrease in the number of bores. Moreover, the rectangular multibores fiber membranes have smaller tensile strength and elongation, i.e., poor mechanical properties. This behavior may attribute to the linear arrangement. Accordingly, the membrane behaves essentially as a feeble ribbon of small strength. The effect of bore fluid flow rate and air gap on tensile strength and elongation percentage was also investigated for all configurations, as displayed in Figs. 15 and 16. The circular and triangular have the maximum mechanical behavior, as previously discussed in the parameter of the dope flow rate.

\section{Application of the MBHF membrane in vacuum membrane distillation}

The PVDF hydrophobic porous membrane is prepared and applied in the vacuum membrane distillation, and Fig. 17 illustrates the SEM of the membrane; it has seven uniform bores and perfectly straight and regular channels, including good smooth surface no peels or scratches.

\section{Contact angle}

The hydrophobicity of the prepared PVDF membranes was assessed through the determination of the contact

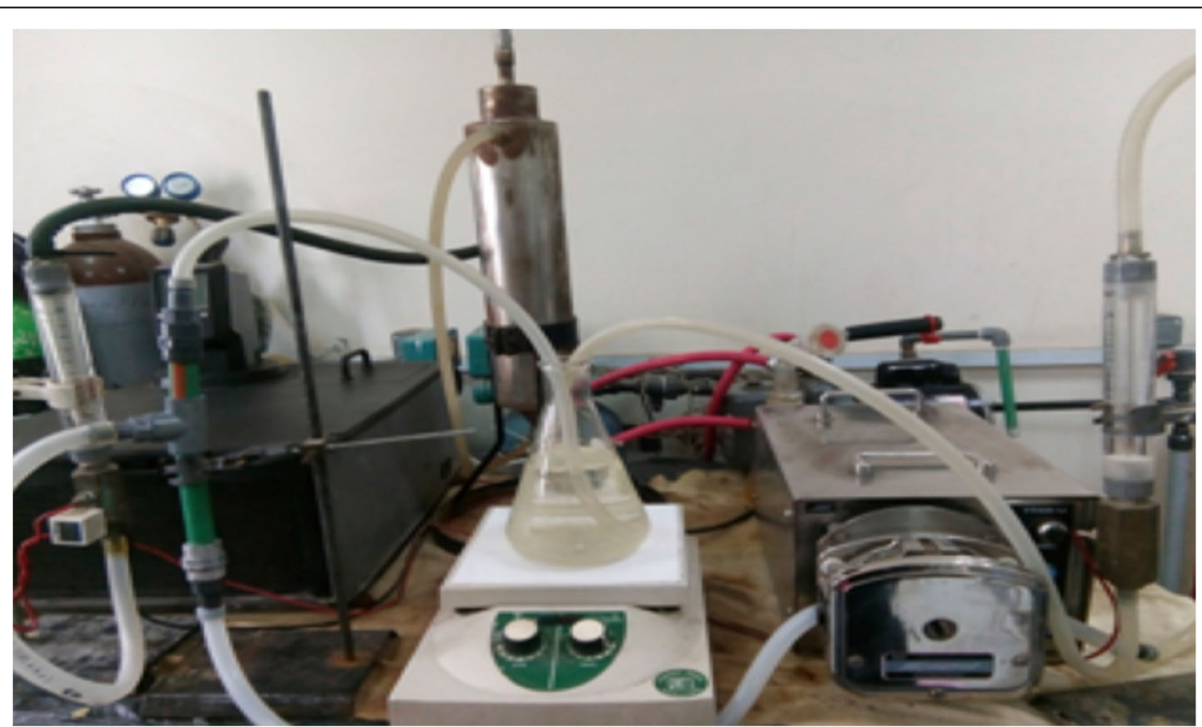

Fig. 19 VMD system used to assess the performance of the TBF membrane 
angle (CA) using the sessile drop method, as shown in Fig. 18; the CA was $\left(128.755^{\circ}\right)$.

\section{Evaluation of the membrane performance}

The performance of the fabricated PVDF MBHF membrane evaluated through a lab-scale VMD system (Fig. 19) using the developed module for the seven BHF membranes. The feed for membrane testing is a $35 \mathrm{~g} / \mathrm{L} \mathrm{NaCl}$ solution to mimic seawater. The operating conditions are the feed temperature of $65^{\circ} \mathrm{C}$ and the volumetric feed flow rate of $8.6 \mathrm{~cm}^{3} / \mathrm{s}$. At the same time, a vacuum pump with a pressure of about $1000 \mathrm{~Pa}$ (absolute pressure) connected to the permeate side of the membrane. The permeate collected and condensed, the permeate volume and salinity are measured. The obtained flux was $28.32 \mathrm{~L} / \mathrm{m}^{2} \mathrm{~h}$, and the rejection was $98.8 \%$.

\section{Conclusions}

In this article, the preparation of MBHF and its application in membrane distillation are developed. Spinnerets of various geometrical configurations are designed, implemented, and used to prepare the membranes for different applications. Three polymeric blends are developed and studied. PB3 gives the prime mechanical properties, and it is selected to study the influencing parameters on the preparation steps. The circular, rectangular, and triangular multi-bore hollow fiber membranes prepared using different spinnerets with circular (4, 5, and 7 bores), rectangular ( 5 bores), and triangular bore nozzles. The outer surface of the membranes and shapes of lumen holes are strongly affected by the dope formulae used to prepare these membranes, bore fluid, and flow rates. A proper bore fluid facilitated the formation of MBHF membranes with desirable shapes and separation performance. The prepared membrane fibers can withstand high load compared to single-bore hollow fibers and flat sheets, which enable this type of hollow fiber membrane to be a great competitor in applications of water reuse and water desalination, particularly in membrane distillation. The membrane is evaluated in a lab-scale vacuum membrane distillation system to assess its performance; it gives flux of $28.32 \mathrm{~L} / \mathrm{m}^{2} \mathrm{~h}$, and salt rejection of $98.8 \%$.

\section{Nomenclatures}

PES Polyethersulfone, polymer

NMP The solvent N-Methyl-pyrrolidone

PVP Polyvinyl pyrrolidone, MW25,000

EG Polyethylene glycol, MW400

DEG Diethylene glycol, MW106.12

LiCl Lithium chloride

MBHF Multi-core hollow fiber

SEM Scanning electron microscope

PB1 Polymeric blend 1PES 16\%, PEG 4\%, acetonitrile $2 \%$, and NMP $78 \%$
PB2 Polymeric blend 2PES 16\%, PVP 4\%, acetonitrile $2 \%$, and NMP $78 \%$

PB3 Polymeric blend 3PES 16\%, PEG 2\%, PVP 2\%, diethylene glycol 2\%, NMP 78\%

VMD Vacuum membrane distillation

$\mathrm{NaCl}$ Sodium chloride solution $(40,000 \mathrm{ppm})$

$J_{\mathrm{W}}$ Permeate flux, $\mathrm{Lm}^{-2} \mathrm{~h}^{-1}$

$V$ Volumetric flow rate of the permeate, $\mathrm{L} / \mathrm{h}$

A Membrane area, $\mathrm{m}^{2}$

SR The salt rejection

$C_{\mathrm{P}}$ Permeate concentration, ppm

$C_{\mathrm{F}}$ Feed water concentration, ppm

\section{Acknowledgements}

Authors would like to thank the Science and Technology Development Fund (STDF), Ministry of Scientific Research Ministry, Egypt, which had funded the project entitled Novel Membranes with Multiple Hollow Holes (MMHH) for Reaction Catalysis to produce biofuel, project ID 9185; grant type, STDFNational Challenges Program (STDF-NCP); and challenge field, catalysts petrochemical industry.

\section{Authors' contributions}

Elham El-Zanati: She is the main author, she had proposed the subject and pursued to provide a financial support for this research, and she is responsible for planning and implementation of this research. Eman Farg: She did the experimental part of membranes preparation. Esraa Taha: She did the experimental part of membranes preparation. Ayman El-Guindi: He was responsible for the determination of the polymer blends. Heba Abdallah: She participated in characterization of the prepared membranes. The authors read and approved the final manuscript.

\section{Funding}

Science and Technology Development Fund (STDF), Ministry of Scientific Research Ministry, Egypt.

\section{Availability of data and materials}

All data generated or analyzed during this study are included in this published article. The manuscript involves the designs of all parts of the used and developed equipment; meanwhile, these data are comparing the similar researches that are available in published references as the included references in the manuscript.

\section{Competing interests}

1. The authors declare that they have no competing interests.

2. Manuscripts did not report any studies involving human participants,

human data, or human tissue.

3. This manuscript did not involve human data or human tissues.

4. This manuscript did not involve animals.

5. This manuscript did not involve any individual person's data (not applicable).

6. It is an engineering article, involves designs, and engineering data.

Received: 3 June 2020 Accepted: 6 October 2020

Published online: 23 October 2020

\footnotetext{
References

Abdallah H, El-Gendi A, Khedr M, El-Zanati E. Hydrophobic polyethersulfone porous membranes for membrane distillation. Front Chem Sci Eng. 2015. https://doi.org/10.1007/s11705-015-1508-4.

Agboola O, Sadiku R, Adegbola A, Biotidara O. Rheological properties of polymers: structure and morphology of molten polymer blends. Mater Sci Appl. 2011;2:30-41 https://doi.org/10.4236/msa.2011.21005.

Bernardo P, Tasselli F, Chiappetta G, Clarizia G. Effect of the post-spinning solvent exchange on the performance of asymmetric, polyimide hollow fibers prepared by using a triple-orifice spinneret. Materials. 2019;12(3632):1-12 https://doi.org/10.3390/ma12213632.
} 
Bonyadi S, Mackley M. The development of novel micro-capillary film membranes. J Membr Sci. 2012;389:137-47 https://doi.org/10.1016/.jmemsci. 2011.10.023.

Chung TS, Wang P. Design and fabrication of lotus-root-like multi-bore hollow fiber membrane for direct contact membrane distillation. J Membr Sci. 2012; 421(422):361-74 https://doi.org/10.1016/j.memsci.2012.08.003.

El-Zanati E, Khedr M, Farag E, Taha. Fabrication of tri-bore hollow fiber (TBF) membrane module for vacuum membrane distillation. Wat Ener Food Env J. 2020;1 (2):25-35 https://doi.org/10.18576/wefej/010203.

El-Zanati $\mathrm{E}$, Abdallah H. Esterification of ethyl hexanoic acid using flow_through catalytic membrane reactor. Catal Ind. 2015;7(2):91-7. https://doi.org/10.1134/ S2070050415020038.

Haase M, Jeon H, Hough N, Kim J, Stebe K, Lee D. Multifunctional nanocomposite hollow fiber membranes by solvent transfer induced phase separation. Nat Commun. 2017:8:1234 https://doi.org/10.1038/s41467-017-01409-3.

Hua D, Ong YK, Wang P, Chung T-S. Thin-film composite tri-bore hollow fiber (TFCTbHF) membranes for isopropanol dehydration by pervaporation. J Membr Sci. 2014;471:155-67 https://doi.org/10.1016/j.memsci.2014.07.059.

Li Y, Biisembaev M, Gong Q, Aknazarov S, Lu F, Huang Y, Zhao X, Du K, Bai J, Gan J, Zhao M, Zhuang D. Preparation of lotus root-type monolithic-activated carbons with an hierarchical pore structure from rice husks and their adsorption of vitamin B12. ACS Omega. 2019;4(20):18930-5 https://doi.org/ 10.1021/acsomega.9b03052.

Liu YH, Benqiao H, Jianxin L, Sanderson R, Li L, Zhang S. Formation and structural evolution of biphenyl polyamide thin film on hollow fiber membrane during interfacial polymerization. J Membr Sci. 2011;373(1):98-106 https://doi.org/10. 1016/j.memsci.2011.02.045.

Lu K, Zuo J, Chung TS. Tri-bore PVDF hollow fibers with a super-hydrophobic coating for membrane distillation. J Membr Sci. 2016;514:165-75.

Peng N, Teoh M, Chung TS, Koo L. Novel rectangular membranes with multiple hollow holes for ultrafiltration. J Membr Sci. 2011;372:20-8 https://doi.org/10. 1016/j.memsci.2011.01.022.

Teoh M, Peng N, Chung TS, Koo L. Development of novel multichannel rectangular membranes with grooved outer selective surface for membrane distillation. Ind Eng Chem Res. 2011;50:14046-54 https://doi.org/10.1021/ ie201292j.

Ullsperger J, Válek R. Properties of polymer solutions intended for formation of hollow fibers membranes by inversion phases process. Appl Rheol. 2018; 28(6):65935 https://doi.org/10.3933/applrheol-28-65935.

Wang P, Chung TS. Design and fabrication of lotus-root-like multi-bore hollow fiber membrane for direct contact membrane distillation. J Membr Sci. 2012; 421(422):361-74 https://doi.org/10.1016/j.memsci.2012.08.003.

Wang P, Luo L, Chung TS. Tri-bore ultra-filtration hollow fiber membranes with a novel triangle-shape outer geometry. Membr Sci. 2014;452:212-8 https:/doi. org/10.1016/j.memsci.2013.10.033.

\section{Publisher's Note}

Springer Nature remains neutral with regard to jurisdictional claims in published maps and institutional affiliations.

\section{Submit your manuscript to a SpringerOpen ${ }^{\circ}$ journal and benefit from:}

- Convenient online submission

- Rigorous peer review

- Open access: articles freely available online

- High visibility within the field

- Retaining the copyright to your article

Submit your next manuscript at $\boldsymbol{\nabla}$ springeropen.com 